on the really practical results obtained in the manufacture of peat-coke, power-gas, and moss-litter. They point out the agricultural capabilities of decomposed black peat soils in Maine (p. 57), and the use of dried peat as an auxiliary fertiliser in composts with barnyard manure, and they especially urge the introduction of air-dried peat as an absorbent in stables and as a deodoriser. Descriptions of special bogs follow, accompanied by neat maps in the text. These bogs have been tested with an ordinary ship-auger (p. 6o), fixed on 2 I feet of $\frac{1}{2}$-inch gas-pipe, and an improved form is described, by which, as in many soil-testers, samples can be still more safely collected at any particular depth. The bogs in Maine appear rarely to be 30 feet deep. As is customary in publications of the United States Geological Survey, sufficient explanations are given of technical terms to enable any intelligent citizen to utilise this handy and scientific treatise.

In the case of the Canadian Survey, general principles have been dealt with in the earlier memoir to which we have referred, and the present bulletin describes in considerable detail certain bogs which possess commercial possibilities, and which lie not far from Ottawa. Lines were run across the bogs, usually Iooo feet apart, and drillings were made in each of these lines at intervals of 500 feet. The samples thus collected were often put together in groups, as representing, when combined, certain areas of the bog: but special local features of interest were noted wherever necessary. An ingenious system of lettering on the maps shows the character of the peat at each point, and its relative suitability for moss-litter or for fuel. The Canadian mode of gathering is by breaking up the surface of the bog so as to promote air-drying, and then stripping off this surface-layer. The bog is thus in most cases worked horizontally, and not vertically, as in Europe. The large scale of the maps inserted in the bulletin, and the completeness of the descriptions, remind one of the fine old bog-survey of Ireland published some eighty years ago, which still remains a standard work of reference. The peat industries of Canada, like those of the United States, are still mostly in an experimental stage, and little more can be said of those organised from time to time in Ireland. Meanwhile, in Europe, at any rate, the humble tiller of the soil, with his old-fashioned hand labour, continues quietly to remove the peat, in which he possesses a clean and economic fuel.

$$
\text { G. A. J. C. }
$$

\section{AN ANTHROPOLOGICAL SURVEY OF THE SUDAN.}

THAT the study of anthropology is of great scientific and practical importance has been acknowledged of late years by various Governments within the Empire. Our readers will remember that the Indian Government assisted Mr. A. R. Brown in his investigation of the Andamanese, and the Ceylon Government two years ago invited Dr. C. G. Seligmann to study the Veddas. The Anglo-Egyptian Administration, as is well known, fully recognises the far-reaching interest which attaches to the natural and human history of Egypt and the Sudan, and directly and indirectly it has done a great deal to extend our knowledge of the meteorology, geology, geography, zoology, botany, and archæology of these regions. In continuance of that enlightened policy, arrangements have been made to organise an ethnographical survey of the Sudan. Those in authority realise that it is impossible to educate or govern a people without some knowledge of their psychology, and no mere facility with their language will suffice without a knowledge of native customs, ceremonies, ideas, and ideals. Especially is it necessary to record the unwritten laws and usages which regulate private and public life and to appreciate the safeguards for personal and social morality which occur in every community. The native conceptions of the relation of the individual to his fellow and of the authority of the head of the local state are very different from those of Europeans, and it would be disastrous suddenly to break up the structure of native society, to weaken authority, or to promulgate revolutionary ideas. It is also recognised by the Sudan Government that failure in the past has been due to lack of scientific knowledge, and they seek to avoid mistakes in the future by acquiring that knowledge upon which a firm and just administration alone can rest.

In the spring of last year the Sudan Government stated that they were prepared to contribute a sum of money sufficient to enable anthropological investigations to be undertaken in the Sudan for at least two years (a part of this sum is set aside for the publication of the results), and Dr. and Mrs. Seligmann were appointed to conduct these investigations. At that time the Seligmanns were still in Ceylon, and as it would take them several months to work up their field-notes, the Sudan expedition was postponed till this year. The Seligmanns leave England on November 2nd, and will proceed with as little delay as possible to investigate the Dinkas and Shilluks in the Upper Nile Province. Probably they will also study the pagan Nubas of Southern Kordofan, and possibly some other tribes as well.

Those who are conversant with recent anthropological literature are fully aware of the competence of Dr. Seligmann to undertake this work. It is significant of the times that Mrs. Seligmann is officially recognised as a co-investigator with her husband. Tudging from what Mrs. Seligmann did in Cevlon, there is no doubt that this enlightened new departure of the Sudan. Government will be fully justified. During a part of the time that the Seligmanns are in the field they will be accompanied by Dr. IV. H. R. Rivers, who will thus be enabled to compare from personal knowledge the systems of kinship and the sociological conditions of Papuans, Melanesians, Polvnesians, and Todas with those of various North Sudanese tribes.

Dr. Seligmann hopes to initiate an anthropometrical survey of the Sudan during the work of the following season.

A. C. Haddon.

\section{NORTH SEA FISHERY INVESTIGATIONS."}

THE. Blue-book before us, which has recently been issued by the North Sea Fisheries Investigation Committee, completes the second report of the Marine Biological Association on the investigations which they have been conducting in the southern part of the North Sea and in the English Channel, in connection with the international investigations of the fisheries of northern Europe.

A memoir by Mr. J. O. Borley describes the experiments which have been made on board the s.s. Huxley in order to determine the probability of survival of trawl-caught fish if they are returned to the sea. From the point of view of the fishery legislator this is a matter of considerable importance, since the probable effect of any law regulating the size at which fish might be placed on the market would depend very largely upon whether or not fish below the legal size, which had been caught in the trawl,

1 North Sea Fisheries Investigation Committee. Second Report (Southern Area) on Fisherv and Hydrographical Investigations in the North Sea and Adjacent Waters, rgo4-5. Part ii. Pp. vt 345; 8 plates. (London: His Majesty's Stationery Office, Igog.) Price $8 s .9 d$. NO. 2086, VOL. 8I] 
would survive if returned to the sea. The experiments were conducted with both otter- and beamtrawls, and show that fish from long hauls of the trawl are much less likely to survive than those from short hauls, and that the otter-trawl, which is now practically exclusively used by steam trawlers, inflicts much more serious injury on the fish than does the beam-trawl. The effect of exposure of the fish on the deck of the vessel for different periods of time has also been studied.

Dr. W. Wallace writes on the subject of the size and age of plaice at maturity. The method used for determining age has been the examination of the otoliths or ear-stones of the fish, the alternate dark and white rings of which form a record of seasonal growth. The most striking result of Dr. Wallace's work is the determination of the fact that the average size and age of plaice at first maturity varies in different regions. In the central part of the North Sea, around the Dogger Bank, female plaice are, on the average, I 6 inches long, and the majority are just six years old when they become mature for the first time. In the southern bight of the North Sea the average size of the females at first maturity is only 13 inches, and the age five years; in the western part of the English Channel the average size is about the same as in the southern North Sea (13 inches), but the average age is four years instead of five, owing to the more rapid growth of the young plaice in the Devon bays. Similar differences are found for the male plaice also, which mature at a smaller size than the females.

The report on records of catches furnished by the captains of Lowestoft sailing-trawlers, which is written by Miss R. M. Lee, shows the value of such records provided by fishermen in supplementing and extending the work done by the scientific steamers. The area worked over by the Lowestoft men corresponds roughly with the southern bight of the North Sea. The analysis of the figures, which Miss Lee has been able to make, indicates that in the northern part of this region plaice occur in maximum quantity by weight during the summer and in minimum quantity during the winter months. In the southern part of the area, on the other hand, the maximum is in winter and the minimum in summer, whilst in the intermediate region there are maxima in spring and autumn. These records, therefore, clearly confirm the southward migration of plaice for the purpose of spawning in winter, which marking experiments in this part of the North Sea had already foreshadowed.

An account of the hydrographical investigations in the English Channel for the years $1904^{-5}$ is contributed by Mr. D. J. Matthews, and is illustrated by a series of very valuable plates, which set forth the results in graphic form by means of coloured charts and sections. The importance of these hydrographical investigations in the English Channel in connection with the problems of North Sea fisheries can scarcely be exaggerated, since the Atlantic water which reaches the southern area of the North Sea comes practicallv exclusively by way of the English Channel. In both the years 1004 and 1905 the salinities in the English Channel reached a maximum in the early months of the year, and fell to a minimum in the summer. The evidence indicates, further, that the movements of the water were more frequent and rapid in 1904 than in 1905. Special attention was given to the conditions prevailing at the mouth of the English Channel, where the two conflicting currents already demonstrated in 1903 were again encountered, a low salinity current flowing southwards from the Irish Channel across the mouth of the Enelish Channel, and a current of No. 2086, VOL. 8I] high salinity entering the Channel from the southwest.

The volume, as a whole, contains a large mass of data of the greatest importance for the solution of many of the problems dealing with marine life, and more particularly with the natural history of fishes. It must be borne in mind, however, that it is essentially a contribution of data to the much wider and more comprehensive scheme of investigation which is being carried out in connection with the International Council, and not until the whole work which the various countries have done has been brought together and the results duly correlated can the full fruit of these researches be gathered.

\section{DOUBLE-STAR STUDIES. ${ }^{1}$}

$A$ COMPLETE record and discussion of the doublestar measures made at the Potsdam Observatory by Prof. Lohse, the director, during the period 1899 to r 908 is given in Publication No. $5^{8}$ of the Observatory. Prof. Lohse employed a refractor made by Schroeder about twenty-five years ago. The objective is eleven inches, and the flint is dark green. It may be described as a good instrument, but not of the highest quality. Nevertheless, we notice that Prof. Lohse was able to secure measures of some difficult pairs, notably $\delta$ Equulei, Pegasi, and Sirius. The filar micrometer has one fixed and one movable thread. Generally the power employed was $55^{\circ}$, but occasionally one of 800 was used. The power ordinarily used with the Greenwich 28 -inch refractor is 670 , and occasionally inzo. Setting out with a definite programme, he chose a working list of I66 double stars made up of known binaries and others of interest, and during the nine years he was making measures of these systems he collected those made by other observers, and hence was in a position to make a useful discussion of his results.

The present volume is therefore divided into two portions. Part $i$. contains the measures made at Potsdam, and part ii. their discussion in combination with measures made since the discovery of each pair. Prof. Lohse uses the method of $Z$ wiers to determine his orbits, and discusses altogether thirty. The actual elements arrived at in most cases differ little from previous orbital elements, and do not call for special remark, except, perhaps, in the cases of $\eta$ Cassiopeiæ and 70 Ophiuchi. The apparent orbit given for $\eta$ Cassiopeiæ does not seem the most suitable, and brings out a period of 345 years, or Ioo years larger than that generally accepted. In the case of $7^{\circ}$ Ophiuchi, Prof. Lohse has done a good piece of work in attacking one of the anomalies often found in double-star orbits. It is found that the differences between the computed and observed positions of the companion tend to periodicity. This may be due to some fault in the gravitational theory, to errors due to personality, or to the effect of some disturbing body. The binaries $\zeta$ Herculis and 7o Ophiuchi are excellent examples of this, and Prof. Lohse, who favours the personality explanation, has taken great pains to compute the relative areas swept out by the companion to 70 Ophiuchi every six months, and obtains figures in agreement with those deduced by quite independent methods. $\mathrm{He}$ is, however, unwilling to admit the reality of the figures, and remarks that by a judicious selection of observations the deviations from the law of equal areas may be reduced. This is the method advocated by Prof. Burnham, but it is not easy to

1 Publikationen des Astrophysikalischen Observatoriums zu Porsdam,
No. 58. Zwanzigsten Bandes, Erstes Stück. Doppelsterne von O. Lohse No. 58. Zwanzigsten Bandes, Erstes Stück. Doppelsterne von O. Lohse
(Director). Pp. 168. (Potsdam, I9o8; in Kommission bei W. Engelmann in Leipzig.) 